\title{
Social Status Predicts Different Mating and Reproductive Outcomes for Men and Women in China: Evidence from the 2010-2017 CGSS Data
}

Yikang Zhang ( $\sigma$ kang.y.zhang@outlook.com )

Maastricht University Faculty of Psychology and Neuroscience: Universiteit Maastricht Faculty of Psychology and Neuroscience https://orcid.org/0000-0001-5173-562X

Pekka Santtila

New York University Shanghai

\section{Research Article}

Keywords: Social status, Mating success, Reproductive Success, Fertility

Posted Date: January 18th, 2022

DOI: https://doi.org/10.21203/rs.3.rs-1005378/v1

License: (c) (i) This work is licensed under a Creative Commons Attribution 4.0 International License. Read Full License 


\section{Abstract}

Evolutionary psychological theories posit that higher social status is conducive to men's reproductive success. Extant research from historical records, small scale societies, as well as industrialized societies, support this hypothesis. However, the relationship between status difference between spouses and reproductive outcomes has been investigated less. Moreover, even fewer studies have directly compared the effect of status and status difference between spouses on reproductive outcomes in men and women. Using data from the Chinese General Social Survey (CGSS) conducted between 2010 and 2017 ( $N=55,875 ; 28,931$ women) and operationalizing social status as standardized income and educational level (compared with same-sex peers), we examined how social status and relative status between spouses impact men's and women's mating and reproductive outcomes. We found that (1) men with higher social status were more likely to have long-term mating (being in a marriage and/or not going through marriage disruption) and reproductive success, mainly through having a lower risk of childlessness; (2) women with higher social status were less likely to have mating and reproductive success; and (3) relative status between spouses had an impact on the couple's reproductive success so that couples, where the husband had higher status compared to the wife, had higher reproductive success. Thus, social status positively impacted men's reproductive success, but relative status between spouses also affected mating and impacted childbearing decisions.

\section{Significance Statement}

In terms of standardized educational level and income among peers, social status positively predicts men's mating and reproductive success in contemporary China. However, while a higher social status increases the probability of having at least one child, it does not predict a greater number of children for men. A status difference between spouses, on the other hand, consistently predicts having children. Thus, the higher the husband's status relative to his wife, the greater the likelihood of having the first, second, and third children. The current results suggest that when examining the effect of status on mating and reproduction, social status and status within a family should be considered. We also stress the importance of exploring the potential proximate mechanisms by which a status difference influences childbearing decisions.

\section{Introduction}

Due to females' higher obligatory parental investment in gestation and lactation compared with males in the case of mammals, including humans (Bateman 1948), females tend to provide more parental care and devote less energy to mating. This tendency, in turn, affects the operational sex ratio (Clutton-Brock 2007), skewing it toward males. Therefore, females can exert their preferences in mate selection, choosing males with a higher social status and more resources thus able to provide more parental investment (Trivers 1972). In humans, it has been found that women are choosier compared to men (Buss 1989, Buss and Schmitt 1993, Buss and Schmitt 2019) and that there is more significant variance in men's reproductive outcomes as a result of sexual selection (Wilder et al. 2004, Betzig 2012).

\section{Social Status Influences Mating and Reproductive Success}

As higher social status is accompanied by more resources being available for rearing offspring and women thus would be expected to prefer higher social status men as their mates (Trivers 1972), men with higher social status should in theory have greater mating success and reproductive success (i.e., more offspring) than men with lower social status. Empirical evidence has consistently shown that, in pre-industrial societies, higher-social status men achieved greater reproductive success (Mealey 1985, Clark and Hamilton 2006, Hu 2020). However, in modern societies, the association between social status and reproductive outcomes is less clear. Some studies have found a null (Freedman and Thornton 1982, Perusse 1993) or negative relationship (Vining 1986) between social status and a man's number of offspring, while others have found a positive relationship (Hopcroft 2006, Fieder and Huber 2007, Hopcroft 2020, Hopcroft 2021). What is worth noting is that although there is no positive relationship between social status and the number of offspring, Perusse (1993) found evidence suggesting that higher social status men had greater potential fertility - that is, higher copulation frequency. Fieder and Huber (2007) found that income was positively associated with reproductive success for men, mainly because they could reduce the risk of childlessness; after excluding men who had no children, the positive association between social status and reproductive outcomes for men became non-significant. Similar relationships between social status and bachelorhood, as well as childlessness, were found in contemporary Sweden (Kolk and Barclay 2021). Hu (2020) found that the positive relationship between men's social status and the number of offspring in historical China became non-significant after controlling for the number of marriages.

Taken together, these results suggest that in the past, a high social status would have contributed to men's reproductive success primarily because of mating success (i.e., a greater number of mates) rather than having more children per partner. This is also consistent with the fact that the maximum number of offspring a woman can have is limited. Note that this explanation does not contradict evolutionary thinking as no prediction of higher social status being associated with an increased desired number of children is made. Instead, it is more likely that the higher reproductive success of high-social status individuals is an indirect result of having more sexual partners (Forsberg and Tullberg 1995) and engaging in more copulations (Perusse 1993, Hopcroft 2006), which would naturally lead to more pregnancies and offspring in the evolutionary 
past, but not necessarily at present. Thus, in modern secular societies where contraceptives are widely used and (serial) monogamy is the norm, the social status-fertility link may be less strong for men. However, based on both theoretical predictions of women's preference for higher social status men (Buss 1989) and previous research examining the social status-reproductive success association in men (Hopcroft 2006, Fieder and Huber 2007, Hopcroft 2021), we would still expect men with higher social status to have greater long-term mating success, leading to a decreased likelihood of having no children at all.

On the other hand, according to parental investment theory, reproductive outcomes tend to vary less for women at different points on the social status dimension compared with men, as lower status women are being selected against less than lower status men. That being said, women with a higher social status are more likely to have fewer children than their lower- social status counterparts in modern societies (Fieder and Huber 2007, Huber et al. 2010). From an evolutionary perspective, the lower fertility of higher social status women may partly originate from the interaction between the tendency for hypergamy and the norm of serial monogamy in modern societies. That is, women tend to marry partners who have a relatively higher social status compared with themselves, which is associated with mating and reproductive success for women (Bereczkei and Csanaky 1996). This tendency, however, could also result in spinsterhood at the top and bachelorhood at the bottom of society (Van Den Berghe 1960) in modern societies with a norm of serial monogamy. Research has shown that women with higher education and career prospects may be less desirable in the marriage market, which may result in lower marriage and fertility rates (Bertrand, Cortes, Olivetti, and Pan 2020, Hwang 2016). As more women enter and succeed in higher education and careers, obtaining higher social status, hypergamy is less and less achievable, especially for high social status women. Indeed, a recent population-based study revealed that educational hypergamy (i.e., the pattern in which husbands have a higher educational level than their wives) is ending, while hypogamy is increasing (Esteve et al. 2016). Research from China also indicates that the expansion of higher education enhances the tendency for educational homogamy among younger cohorts (Hui and Qian 2016). Therefore, higher social status women may have lower mating success leading to decreased reproductive success (for opposing evidence in recent Western cohorts, see Budig and Lim 2016, Torr 2011).

Though women's fertility along the social status dimension can be influenced by evolutionary logic, other important factors have been proposed and studied. Firstly, pursuing higher education and participating in the labour market tends to delay the age of a woman's first marriage (Ikamari 2005), thus postponing reproduction (Mills et al. 2011). Moreover, the anticipation and planning of marriage can also impact women's education levels. Research shows that in specific settings (e.g., rural India), the perceived incompatibility between higher education and preferred age of marriage in women is more significant, which impacts the parents' decision towards their daughter's education (Maertens 2013). Secondly, the cost of rearing a child increases as social status rises. Borg (1989) found that after controlling for the estimated net cost of a child, calculated by the sum of a child's cost and benefits and the mother's opportunity cost, the negative relationship between income and fertility became positive. Thirdly, evidence suggests that childbirth negatively affects women's employment and income (Hofferth and Curtin 2006, Takeuchi and Otani 2007, Ejrnæs and Kunze 2013), suggesting a bi-directional relationship. All of these point to the complexity of the mechanisms involved.

Taken together, we hypothesized higher social status to be associated with greater mating success (staying in a marriage) and reproductive success for men but less mating success and reproductive success for women. More specifically, we hypothesized that:

1. Higher social status increases the likelihood of being married for men but decreases it for women (H1).

2. Among those who were or have been in a marriage, higher social status decreases the likelihood of marriage disruption for men but increases it for women $(\mathrm{H} 2)$.

3. Higher social status increases reproductive success for men but decreases it for women (H3).

\section{The Association of Social Status Difference between Spouses and Their Mating and Reproduction}

Besides influencing men and reproductive outcomes via mating success, the tendency for hypergamy can also influence the reproductive outcomes among those who have entered a marriage. That is, the social status difference between partners may also impact reproductive outcomes. Women who marry higher social status men and men who choose younger women as mates have significantly more surviving children than those who pursue alternative mating strategies (Bereczkei and Csanaky 1996). A recent study from China found that women's relatively higher social status compared to their partners negatively predicted the intention of having a second child (Qian and Jin 2018). Indirect evidence from marital quality also suggests that the social status difference between partners is important. Women who have higher relative social status compared with their male partner were more likely to suffer from domestic violence (Kaukinen 2004, Kayaoğlu 2020), which from an evolutionary point of view, can be conceptualized as a male's mate retention tactic (Shackelford et al. 2005, Kaighobadi et al. 2009).

Moreover, women who have a relatively higher social status compared with their partner were more likely to separate and divorce (Heckert et al. 1998, Liu and Vikat 2007), though in recent US cohorts, this relationship seems to no longer hold (Schwartz and Gonalons-Pons 2016; Schwartz and Han 2014). Therefore, we hypothesized that among first-time married couples, the higher the relative social status of the husband compared with the wife, the greater will be their reproductive success $(\mathrm{H} 4)$. We restricted this hypothesis to first-time married couples because the current 
dataset neither recorded individuals' fertility by marriage nor contained social status information about the respondents' ex-partners. Therefore, using the relative social status of the current partners to predict fertility through multiple marriages is theoretically problematic.

Age at first marriage can serve as an indicator of mating success in humans. Using historical data, Telford (1992) showed that higher social status is associated with earlier marriage for sons in China. As there is a trade-off between spending time searching for high-value partners and securing an available mate to reproduce with, men who have a relatively higher social status than their future partner may enter into marriage earlier than those not in this advantageous position. We hypothesized that for women, however, the tendency for hypergamy predicts that higher social status women may face more difficulty finding satisfactory partners, increasing the marriage age (H5). Evolutionary psychology also predicts that compared with women, men tend to prefer younger mates who are more fecund (Kenrick and Keefe 1992). However, men's reproductive function is less influenced by ageing than women, and wealth tends to accumulate with age. Therefore, men may make trade-offs between their partners' social status and age, but not women. We hypothesized that men who marry women of relatively lower social status than themselves have younger wives than those men who marry up. In comparison, women who marry men of relatively lower social status than themselves do not have younger husbands than those who marry up ( $\mathrm{H} 6)$. Note that in both hypotheses 5 and 6 , we only propose the negative relationships due to trade-offs and do not state that the social status difference causes changes in the age of marriage.

The relationships hypothesized in H1-3 have been partially examined and supported in previous studies (Hopcroft 2006, Fieder and Huber 2007, Hopcroft 2021) using WEIRD (Henrich et al., 2010) data. Thus, the corresponding analyses in the current study will be conceptual replications using different statistical methods and data (see Methods section). However, examining how the relative social status between married couples affects their mating and marriage outcomes (H4-6) has been studied less directly and, therefore, represents a relatively novel contribution to the literature.

\section{Social Status and Reproduction in China}

In China, the fertility rate has been declining due to social and economic development and the state's policy on birth control (Lavely and Freedman 1990, Cai 2010, Piotrowski and Tong 2016) dating from the 1970s (Wang 2012). Thus, a popular conception of fertility decline in China is that the family planning policy mainly drives it. However, research has suggested that social and economic development play a more critical role, like other countries that have experienced a demographic transition (Cai 2010). Furthermore, previous research on social status and fertility in China has only focused on women's fertility and found that education was negatively associated with fertility and childbearing intentions (Zheng et al. 2016), consistent with findings from other countries (Fieder and Huber 2007, Huber et al. 2010). Therefore, it is reasonable to assume that despite being influenced by a strict policy, Chinese data remains suitable for examining the social status-fertility link.

Moreover, it is difficult, if not impossible, to find a modern industrialized state where the natural fertility of humans may be studied without the influence of any societal structures. As mentioned above, other countries have influenced fertility patterns by social policies (Jalovaara et al. 2019), albeit in the opposite direction. Analyses based on these data have been published and considered as evidence either for or against evolutionary hypotheses. Therefore, results from China are not just acceptable but essential for developing an unbiased understanding of the hypothesized social status-fertility link. However, at this moment, less is known about how social status impacts men's marriageability and fertility in China. Thus, whether one of the central hypotheses in evolutionary psychology - higher social status positively influences mating and reproductive success for men - still holds in China is unknown and demands investigation.

\section{Method}

\section{The CGSS Data}

The Chinese General Social Survey (CGSS, http://cgss.ruc.edu.cn/) is a cross-sectional, nationwide social survey administrated by the National Survey Research Center at Renmin University of China conducted annually since 2003. The cycle-2 sampling design (2010-2019) uses a multistage sampling method (140 primary selection units and 480 secondary selection units) to collect representative urban and rural household data from 31 provinces, autonomous regions, and municipalities. The response rates of the surveys in the current analysis ranged from 71.5 to $74.3 \%$.

The data employed in our research came from the 2010-2017 CGSS (2014 and 2016 data were unavailable), containing 55,875 ( $N_{\text {female }}=$ $28,931)$ face-to-face interviews with respondents born since 1945 who were at least 18 years old when surveyed. The reasons behind restricting the cohorts from 1945 onward were twofold. The first is that China instituted its primary education system in 1952 (Liao, 2019), so collapsing earlier cohorts with later ones when examining the effects of education may not be a good approach. Second, family planning began around 1970 in China and impacted the fertility of Chinese families. Combined with a cultural preference for male offspring, this has resulted in higher rates of abortions targeting female foetuses and a skewed sex ratio (Ding and Hesketh 2006). Restricting the sample to cohorts from 1945 makes it relatively homogenous in terms of the family planning policy, as the 1945 cohort entered adulthood around the starting point of this 
policy. Although, it is also worth noting that, within this period of family planning, the policies of different stages may impact the social statusfertility link differently with the one-child policy in the 1990 s, having the potential to attenuate the relationship to a greater extent.

\section{Variables}

\section{Social Status Indicators in the CGSS}

The annual total income (in CNY) of the interviewees, their partners, and their annual household income was the self-reported sum of income from all sources during the previous year, with an upper limit of 'over 1,000,000 CNY'. Further, the educational levels of the interviewees and their partners have been measured continuously from $1=$ 'no education at all' to $13=$ 'graduate degree and above'.

\section{Social Status Variables in the Current Analyses}

Standardised Income Level. In the current analyses, the annual incomes of respondents were first log-transformed, then standardised according to the respondent's region, sex, and year of the survey.

Standardised Educational Level. We standardised the continuous measurement of educational level based on five-year cohorts, sex, and respondents' regions.

Absolute Educational Attainment. We recoded total education level into four categories: below high school, high school and equivalent, college or bachelor's degree, and graduate degree and above.

Household Income. Household Income was first log-transformed, then mean-centred based on regions and the year of the survey.

Educational Difference between Spouses. We calculated educational differences in two steps: (1) subtracting the raw measure of the educational level of the respondent's spouse from their own educational level, and (2) arranging the educational differences into deciles. Therefore, in the analyses, an educational difference of 1 indicates the respondent has an extremely low social status compared with their spouse, while an educational difference of 5 or 6 would show educational homogamy. The reason for arranging educational differences into deciles is that extreme values of raw differences can affect the regression results. Raw educational differences ranged from -12 to 11 (only one observation each), with a standard deviation of 2.10 and a mean of 0.03 .

Income Differences between Spouses. We calculated income differences by subtracting the log-transformed annual income of the respondent's spouse from their own log-transformed annual income.

Because of the rapid expansion of education in China (e.g., in this dataset, $16.4 \%$ of the $1945-1950$ cohort have a high school/vocational school diploma, while 70.9\% obtained a diploma in the 1990-1995 cohort) and regional inequality in economic development (Yang 2002), the current analyses scaled income and education to locate respondents' social status more accurately. This was done by accounting for the differences in living costs, the dissemination of education among different cohorts and regions, and income inequality between the sexes. We acknowledge that these standardisation operations resulted in examining only the effect of social status (i.e., relative position compared with others), neglecting the effect of the absolute level of financial resources. We simultaneously put absolute (i.e., diplomas obtained) and standardised education levels (i.e., education level compared with same-sex peers in the same region) into models. We hoped to differentiate the multiple mechanisms by which education impacts mating and reproduction. Standardised education level and absolute educational attainment were only moderately correlated, $r(55,775)=.29, p<.001$, suggesting a level of collinearity that would not severely affect the regression results.

\section{Mating and Reproductive Success}

Marital status. Marital status was measured using a multiple-choice question including seven categories: unmarried, cohabitation, married, remarried, divorced, separated, and widowed in the CGSS2011-2017. In the CGSS 2010, no distinction was made between married and remarried. Unmarried refers to the status of being single and never having been married. In our analysis, we recoded those who reported being married but whose year of current marriage and year of the first marriage was not the same as remarried. All six categories except married (for the first time) were dummy-coded.

Number of Children. The number of children was measured by asking participants for their total number of sons and daughters, including stepchildren, adopted children, and deceased children. CGSS2017 also asked participants for the total number of biological sons and daughters, including deceased biological children, but the size of this subsample is limited. Therefore, to maintain the consistency of our analyses, we only reported the results for the number of children. Thus, we calculated the number of children as the sum of sons and daughters. 
Age of Marriage. The age of marriage for the interviewee and their partners were calculated by subtracting their birth year from the year of their marriage. As the current dataset did not record the complete history of the interviewees, we restricted the analyses to first-time married couples only to avoid any confounding from multiple marriages.

\section{Statistical Analyses}

Data Preparation. Before the statistical analyses, we reviewed the age of first marriage and number of offspring to identify and remove extreme values (e.g., age of marriage below 10, 59 cases; the number of son or daughters greater than 20, 4 cases) that were likely to be a result of data entry mistakes or misreporting.

Modelling. We conducted all statistical analyses using R (version 4.10). We used Ime4 (Bates et al. 2015) to perform a series of (generalised) linear mixed-effects analyses using individual weights provided in the CGSS data. First, we examined the effect of marital status on the number of children (results can be accessed in supplementary materials). Then, we examined the impact of social status as operationalized by standardised income, education level on mating success ( $\mathrm{H} 1$ : getting married, and $\mathrm{H} 2$ : going through marriage disruption), and reproductive success $(\mathrm{H} 3)$ while controlling for absolute educational attainment. Because of the sample size limitation, it was unrealistic to analyse data in separate cohorts. An offset variable is often used to control the differences of exposure length in Poisson or logit regressions (Hutchinson and Holtman 2005). Therefore, when examining the number of children, we used Poisson regression with age as an offset variable; that is, we entered logged age in the regression with a fixed coefficient of 1 . As a result, the variables were predicting the rates in these models instead of counts (Gagnon, Doron-Lamarca, et al., 2008). We used logit regression with age as an offset variable for the models with binary outcomes (e.g., childless, unmarried, and marriage disruption). In addition to social status, we also examined how relative social status between partners in terms of standardised income and education affects a couple's reproductive outcome ( $\mathrm{H} 4$ : the number of children) and how relative social status between partners is associated with age at first marriage (H5: age at first marriage of the participant and H6: age at first marriage of their spouse) using (generalised) linear mixed models. While examining how status differences between couples may affect reproductive outcomes, we controlled for household resources (i.e., annual household income centred by regions and year) and the average education level of the couple. In all models, we used random intercepts for regions and cohorts. R code for data preparation and analyses can be accessed at OSF (https://osf.io/dhgqc/?view_only=48465aa7e9c44ca687d4fc95c860f48e).

\section{Results}

Before examining the associations between social status and mating, as well as reproductive outcomes, we first examined the associations between marital status and reproductive outcomes. Compared with those who were married for the first time, being unmarried (men: $B=-3.03, p$ $<.001$; women: $B=-3.22, p<.001$ ), cohabiting (men: $B=-0.30, p<.001$; women: $B=-0.17, p=.003$ ) or divorced (men: $B=-0.39, p<.001 ;$ women: $B$ $=-0.27, p<.001)$ were associated with fewer children in both men and women. Being remarried was associated with more children in both men $(B$ $=0.13, p<.001)$ and women $(B=0.15, p<.001)$ (see supplementary materials for detailed regression results).

\section{Effect of Social Status on Long-term Mating Success and Reproductive Outcomes}

Both absolute educational attainment and standardised educational level, as well as income, were significant predictors of being unmarried for men and women (see Table 1). Specifically, sex interacted with standardised educational level and personal income to predict being unmarried. A higher standardised educational level and personal income decreased the probability of being unmarried for men. Meanwhile, a higher standardised income was associated with a greater likelihood of being unmarried for women, while standardised education level had no significant effect (supporting $\mathrm{H} 1$ ). Absolute educational attainment predicted being unmarried similarly for men and women, with higher educational attainment increasing the likelihood of being unmarried. Excluding those who were unmarried and cohabiting (i.e., those who had never been married), we conducted a second analysis to examine the predictive power of standardised income and education on the likelihood of going through marriage disruption (i.e., divorce or separation, Heckert et al., 1998). Results from Table 2's right-half columns show that men with a higher standardised education and higher standardised income were less likely to experience marriage disruption. However, higher standardised education and income for women were both associated with a higher likelihood of marriage disruption (supporting H2). As for absolute educational attainment, compared with those who had high school level education, men and women who had a college education and above were less likely to go through marriage disruption. For men, those with less than a high school education were also less likely to go through separation or divorce. Robustness checks were run with different independent variables in the models (i.e., sex and standardized income; sex, standardized educational level, and absolute education attainment; sex, the summed score of standardized income and educational level, and absolute education attainment). The results were similar to the ones presented in Table 1 (see Table S2 in supplementary materials).

For reproductive outcomes, we first examined how standardised personal income and education were associated with men's and women's total number of children while controlling for absolute educational attainment. Results showed that standardised personal income and education 
level were significant positive predictors of the number of children for men and significant negative predictors for women (see Table 2). Conversely, absolute educational attainment negatively predicted the number of children for both men and women. Robustness checks were also run with different independent variables and the results were similar to the ones presented in Table 2 (see Table S3 in supplementary materials).

Even though the number of children is count data, one of the assumptions of Poisson regression is that each child's birth is independent, which is not likely to hold up. Therefore, for more accurate analyses, we also ran logit models to examine how standardised personal income, education level, and absolute educational attainment predicted the following: having at least one child, having at least a second child among those who had children, and having at least three children among those who had two or more children. Results are presented in Table 3 . For men, a higher standardised income increased the probability of having the first child but had no significant association with having a second child and decreased the likelihood of having a third child. Moreover, a higher standardised education increased the probability of having the first child, reduced the likelihood of having a second child, and did not predict having a third child. For women, a higher social status in terms of standardised education and income decreased the probability of having the first, second, and third children (supporting $\mathrm{H} 3$ ). The upper panels of Figure 1 present the proportion of having at least one child along with income and standardised education deciles. As for absolute educational attainment, higher education levels were associated with a decreased likelihood of having children for both men and women. However, women with a graduate degree were more likely to have a second child than their high school-educated counterparts.

\section{Effects of Status Differences on Mating and Reproductive Outcomes}

We examined how relative social status between spouses was associated with reproductive outcomes among first-time married couples. Table 4 presents how a spouse's income and education relative to their partner's predicted the likelihood of having children. In all models, we controlled for the average absolute education level (continuous measure) of the couple and household income. For men, higher relative social status than the spouse in terms of education and income was associated with a greater likelihood of having the first and second child. Higher education relative to the spouse, but not income, also increased the probability of having a third child. For women, the pattern was the opposite; higher relative social status in terms of education and income was associated with a decreased likelihood of having the first and second child. A higher education level relative to the partner, but not income, was also associated with a reduced chance of having a third child (supporting $\mathrm{H} 4$ ). Robustness checks without controlling for household income and average education level were run and the results were similar to the results presented in Table 4 (see Table S5 in supplementary materials).

Based on the assumption that, in general, men marrying early in life represents mating success and the trade-off between relative social status and a potential partner's availability for marriage, we predicted that those with a relatively higher social status than their partner would marry at a younger age. The model results support this hypothesis (see Table 5 and Figure 1). A higher relative social status than one's spouse, proxied by education and income differences, was associated with a lower age at first marriage in men. Conversely, in women, income and education had the opposite effect in predicting the age of first marriage, with higher relative status predicting an older age for a first marriage (supporting $\mathrm{H} 5$ ). A higher income and education level relative to their spouse predicted that men married a younger wife after controlling for their own age (supporting $\mathrm{H6}$ ). For women, a higher education level relative to the spouse also negatively predicted the spouse's age (going against $\mathrm{H6}$ ). However, the effect was significantly smaller (see Table S4 supplementary materials for the interaction effect of sex and education difference on partner's age).

\section{Discussion}

We utilized the 2010-2017 CGSS data to examine how social status is associated with Chinese men and women's mating and reproductive outcomes. In our analyses, due to the rapid expansion of education over the last few decades in China, we used statistical operations to separate the effect of standardized educational level (among same-sex peers) and absolute educational attainment. The results suggest that social status measured by standardized education level and income still predict reproductive success in terms of marital status and whether there are offspring in contemporary China. Furthermore, relative social status between spouses predicted the likelihood of having children and age at marriage among first-time married couples.

\section{Effects of Social Status on Mating and Reproductive Outcomes}

After isolating the effect of absolute educational attainment, men with a higher social status than their peers in terms of standardised education and income were more likely to be in a long-term relationship and stay in it. This result is consistent with the evolutionary hypothesis that higher social status is conducive to men's mating success. In contrast, for women, social status had the opposite effect. However, the results do not warrant the conclusion that higher social status women have lower long-term mate value in the eyes of men. Although educated women have been perceived as less desirable, especially in cultures holding traditional gender roles (Bertrand, Cortes, Olivetti, and Pan 2020, Hwang 2016), this decreased desirability may reflect the status concerns of men rather than the low mate value of high- social status women.

Page $7 / 17$ 
Furthermore, past research has suggested that women exhibit greater hypergamy than men (Van Den Berghe 1960). Therefore, women with higher income may tend to choose from men who earn more than they do, and as a result, they face a much smaller mating pool, increasing the difficulty of finding a suitable long-term mate. On the other hand, men may also prefer women who have equal or lower social status compared with themselves, which has been a successful reproductive strategy in the past (Bereczkei and Csanaky 1996). The penalty educated women face in the mating market (Bertrand, Cortes, Olivetti, and Pan 2020, Hwang 2016) may result from social status concerns men may have (i.e., men may prefer to have partners who have relatively lower social status).

As for reproductive outcomes, a higher standardised income and education level were associated with more children for men. However, closer examination revealed that standardised education and income were only significant in predicting the first child for men. For women, a higher social status was associated with a decreased likelihood of having children. Combined with previous studies showing that the social statusfertility relationship is primarily driven by the high risk of childlessness among lower social status men (Kolk and Barclay 2021), the current results suggest that social status, in terms of income and standardized education level, positively contribute to men's but not women's reproduction. This is done through mating success and a better chance at transitioning to parenthood instead of having more offspring in an industrialized societal setting. Moreover, the current results are consistent with previous studies in Western populations (Hopcroft 2006, Fieder and Huber 2007, Hopcroft 2021), suggesting that Chinese data are an appropriate and integral part of evolutionary demographic research. However, it is also important to note that fertility is a complex issue that is not only influenced by an individual's social status but also societal changes (Newson et al., 2007), culture (McQuillan 2004), social welfare (Mills et al. 2011), and family planning policies (Liu and Liu 2020). Specifically, the way in which social status is associated with fertility change depending on regional or national social policies. For example, in more recent cohorts in Nordic countries, the negative relationship between women's educational level and fertility is diminishing due to social welfare reforms (Jalovaara et al., 2019).

\section{Relative Status between Spouses for Predicting Mating and Reproductive Outcomes}

Men who married relatively lower-social status women entered their marriages earlier and married a younger wife compared with those who married relatively high-social status women. This result is consistent with our hypothesis that men may make a trade-off between their partners' social status (relative to themselves) and availability, as well as fecundity. However, as women do not necessarily prefer younger men as mates, we did not hypothesize a relationship between women's status relative to their partner and their partner's age. From Figure 1, it is clear that women with a higher social status than their spouses married later and had older spouses. However, after controlling for their own age, we did find a weaker but significant negative effect of educational difference on the partner's age for women. Therefore, though women with relatively higher social status compared with their spouses had older spouses, this pattern is mainly driven by the fact that higher social status women enter marriage at an older age.

For reproductive outcomes, men who had higher relative social status than their spouses were more likely to have children. On the other hand, women were less likely to have children if their relative social status was higher. Notably, this pattern was significant after controlling for the couple's household income and average educational level, suggesting that relative social status in terms of resource potential may impact women's childbearing decisions. In Figure 1, it is easy to see that besides hypergamy, homogamy is also associated with higher reproductive success. This is consistent with previous research, suggesting that both hypergamy and homogamy are successful strategies (Bereczkei and Csanaky 1996). The current results indicate that the relative social status difference between partners is more useful in predicting reproductive outcomes.

One may be concerned that the observed relationship could be explained solely by women, not men, being more likely to stop their education after having their first child and, thus, having a lower education level than their husbands. Another mechanism for this phenomenon, that does not require an evolutionary strategic explanation, would be personality differences. That is, women with stronger career motivations may devote more energy to advancing their social status and are, thus, less likely to have children. Both hypotheses would receive additional support if the observed phenomenon were present only in cases with a higher educational background. However, using only cases where education was no higher than high school or its equivalent (i.e., a subset where childbirth conflicts less with pursuing an education and a career), we replicated the findings that if the male partner has a relatively higher social status, the couple will have higher fertility (see Table S6 in supplementary materials). As for evolutionary explanations, whether the relationship is because women are more likely to bear children if their partner has a relatively higher social status or because women's relative social status versus their partner's is simply a more accurate way to measure social status within a subpopulation, demands further research. If the former is true, investigating whether this pattern is driven by a worse relationship associated with hypogamy (Kaukinen 2004) could also be a research topic of both theoretical and practical value. It could inform policymaking that may ameliorate the fertility decline, such as promoting a culture where social status is less determined by personal income and education and more associated with aspects of familial and social life. 


\section{Limitations and Future Directions}

Though the CGSS data provided us with a large representative sample with several mating and reproductive success measures, it has several limitations. First, in measuring reproductive success, most of the surveys in CGSS did not differentiate between biological versus non-biological children, nor did the measurements exclude children who were deceased before reaching the age of reproduction. Second, the surveys were not linked with official records. Thus, the data could suffer from inaccurate self-reporting, especially for men's reproductive success (Hopcroft 2021), which is also supported by the current analysis that, on average, women $(M=1.57, S D=1.06)$ had significantly more children than men $(M=$ $1.43, S D=1.04), F(1,55653)=256.6, p<.001$. Third, income from the previous year is not an accurate measure of social status compared with wealth. This might explain the fact that standardized education was a slightly better predictor in our models. Finally, the analyses only provide correlational, but not causal, evidence due to its cross-sectional design. These limitations should be noted when making inferences.

As for the analyses, to make the current research more focused and concise, we controlled regional and ecological differences with random intercepts for rural and urban areas for each provincial region. However, it is well acknowledged that in China, rural-urban dualism (Zhang, Sun, and Liu 2021) and ecological features such as agricultural style (Talhelm and English 2020) impact behavioural patterns. Therefore, how these differences are reflected in reproductive decisions and outcomes should be conceptualized and examined.

Regarding the interpretations of the findings, especially for the sex differences found in our research, we should consider the cultural and demographical differences between China and other regions. For example, the sex ratio bias in China could also be a causal factor for the above results. Because the sex ratio is biased toward men, women would, in theory, have more bargaining power in the mating market, biasing both sexes toward high investment. The potential influence of the family planning policy should also be taken into consideration. The fact that social status only positively predicted the likelihood of having the first child for men could result from the former one-child policy in China rather than reflect an inherent feature of the social status-reproduction relationship.

Studying the relationship between social status and reproductive success is only part of the picture. Thus, researchers should also integrate findings from other areas of evolutionary science - for example, the study of personality and individual differences conferring social status (Durkee, Lukaszewski and Buss 2020), and behavioural genetics that links traits and genes (for a recent review, see Harden 2021). Specifically, recent research examining how the education-reproduction link could influence human population genetics found that because of the negative relationship between education and reproduction, selection has favoured genetic variants associated with low educational attainments (Beauchamp 2016; Kong et al. 2017). Future research could extend our understanding by investigating the relationships between social statusconferring traits (phenotypes), genetics, and educational and financial achievements together and contextualizing the observed patterns by incorporating cultural and ecological factors.

\section{Conclusions}

While social status is associated with mating and reproduction, the data from China are still limited. Our research explored how standardised income and education were associated with mating and reproductive outcomes using the cycle-2 CGSS data. Our results showed that higher social status is associated with more mating and reproductive success for men. Conversely, higher social status predicts lower mating success and reproductive outcomes for women.

Furthermore, relative social status between married couples was associated with mating and reproductive outcomes. Men who had a relatively high social status than their spouses married earlier with younger wives and were likely to have more children. The pattern was the opposite for women. The results were consistent with the evolutionary hypothesis that higher social status contributes to mating success for men. However, more research is needed to establish causation and to disentangle the specific mechanisms.

\section{Declarations}

\section{Conflict of Interest}

The authors declare that there is no conflict of interest.

\section{Data Availability}

The anonymized CGSS data can be accessed at Chinese National Survey Data Archive (http://www.cnsda.org/index.php?r=users/create).

\section{Funding}


The current research is supported by the China Scholarship Council (NO.202106140025).

\section{References}

1. Bateman, A. J. (1948). Intra-sexual selection in Drosophila. Heredity 2:349-368.

2. Bates, D., Mächler, M., Bolker, B. and Walker, S. (2015). Fitting linear mixed-effects models using Ime4. Journal of Statistical Software 67(1): $1-48$

3. Beauchamp, 2016. Genetic evidence for natural selection in humans in the contemporary United States. Proc. Natl. Acad. Sci. U.S.A. 113 (28) (2016), pp. 7774-7779

4. Bereczkei, T. and Csanaky, A. (1996). Mate choice, marital success, and reproduction in a modern society. Ethol Sociobiol 17(1): 17-35

5. Betzig, L. (2012). Means, variances, and ranges in reproductive success: comparative evidence. Evol Hum Behav 33(4): 309-317

6. Buss, D. M. (1989). Sex differences in human mate preferences: Evolutionary hypotheses tested in 37 cultures. Behav Brain Sci 12(1): 1-14

7. Budig, M. J. and M. Lim (2016). "Cohort Differences and the Marriage Premium: Emergence of Gender-Neutral Household Specialization Effects." Journal of Marriage and Family 78(5): 1352-1370.

8. Buss, D. M. and Schmitt, D. P. (1993). Sexual strategies theory: an evolutionary perspective on human mating. Psychol Rev $100(2)$ : 204 - 232

9. Buss, D. M. and Schmitt, D. P. (2019). Mate preferences and their behavioral manifestations. Annu Rev Psychol 70: 77-110

10. Cai, Y. (2010). China's Below-Replacement Fertility: Government Policy or Socioeconomic Development? Popul Dev Rev 36(3): 419-440

11. Clark, G. and Hamilton, G. (2006). Survival of the richest: the Malthusian mechanism in pre-industrial England. J Econ Hist 66(3): 707-736

12. Clutton-Brock, T. (2007). Sexual selection in males and females. Sci 318(5858): 1882-1885

13. Ding, Q. J. and Hesketh, T. (2006). Family size, fertility preferences, and sex ratio in China in the era of the one child family policy: results from national family planning and reproductive health survey, Brit Med J 333(7564):371-373

14. Durkee, P. K., Lukaszewski, A. W., and Buss, D. M. (2020). Psychological foundations of human status allocation. Proc. Natl. Acad. Sci. U.S.A. 117(35): 21235-21241.

15. Ejrnæs, M. and Kunze, A. (2013). Work and Wage Dynamics around Childbirth. Scand J Econ 115(3): 856-877

16. Esteve, A., Schwartz, C. R., Van Bavel, J., Permanyer, I., Klesment, M. and Garcia, J. (2016). The end of hypergamy: Global trends and implications. Popul Dev Rev 42(4): 615-625

17. Fieder, M. and Huber, S. (2007). The effects of sex and childlessness on the association between status and reproductive output in modern society. Evol. Hum. Behav 28(6): 392-398

18. Forsberg, A. J. L. and Tullberg, B. S. (1995). The relationship between cumulative number of cohabiting partners and number of children for men and women in modern Sweden. Ethol Sociobiol 16(3): 221-232

19. Freedman, D. S. and Thornton, A. (1982). Income and Fertility: The Elusive Relationship. Demography 19(1): 65-78

20. Harden, K. P. (2021). “Reports of My Death Were Greatly Exaggerated”: Behavior Genetics in the Postgenomic Era. Annu. Rev. Psychol. 72(1): 37-60.

21. Heckert, D. A., Nowak, T. C. and Snyder, K. A. (1998). The Impact of Husbands' and Wives' Relative Earnings on Marital Disruption. J Marriage Fam 60(3): 690-703

22. Henrich, J., S. J. Heine and A. Norenzayan (2010). The weirdest people in the world?. Behav Brain Sci 33(2-3): 61-83.

23. Hofferth, S. L. and Curtin, S. C. (2006). Parental Leave Statutes and Maternal Return to Work After Childbirth in the United States. Work and Occupations 33(1): 73-105

24. Hopcroft, R. L. (2006). Sex, status, and reproductive success in the contemporary United States. Evol Hum Behav 27(2): 104-120

25. Hopcroft, R. L. (2021). High income men have high value as long-term mates in the U.S.: personal income and the probability of marriage, divorce, and childbearing in the U.S. Evol Hum Behav. 42(5): 409-417.

26. Hu, S. (2020). Survival of the Confucians: social status and fertility in China, 1400-1900. Economic History Working Papers (307). London School of Economics and Political Science, London, UK.

27. Hu, A. and Z. Qian (2016). Does higher education expansion promote educational homogamy? Evidence from married couples of the post80s generation in Shanghai, China. Social Science Research 60: 148-162.

28. Huber, S., Bookstein, F. L. and Fieder, M. (2010). Socioeconomic status, education, and reproduction in modern women: An evolutionary perspective. Am J Hum Biol 22(5): 578-587

29. Hutchinson, M. K. and Holtman, M. C. (2005). Analysis of count data using poisson regression. Res Nurs Health 28(5): 408-418

30. Ikamari, L. D. E. (2005). The effect of education on the timing of marriage in Kenya. Demogr Res 12: 1-28 
31. Jalovaara, M., Neyer, G., Andersson, G., Dahlberg, J., Dommermuth, L., Fallesen, P. and Lappegård, T. (2019). Education, Gender, and Cohort Fertility in the Nordic Countries. Eur J Popul 35(3): 563-586

32. Kaighobadi, F., Shackelford, T. K. and Goetz, A. T. (2009). From Mate Retention to Murder: Evolutionary Psychological Perspectives on Men's Partner-Directed Violence. Rev Gen Psychol 13(4): 327-334

33. Kaukinen, C. (2004). Status Compatibility, Physical Violence, and Emotional Abuse in Intimate Relationships. J Marriage Fam 66(2): $452-471$

34. Kayaoğlu, A. (2020). Do Relative Status of Women and Marriage Characteristics Matter for the Intimate Partner Violence? J Fam Issues.

35. Kenrick, D. T. and Keefe, R. C. (1992). Age preferences in mates reflect sex differences in human reproductive strategies. Behav Brain Sci 15(1): 75-91

36. Kolk, M. and Barclay, K. (2021). Do income and marriage mediate the relationship between cognitive ability and fertility? Data from Swedish taxation and conscriptions registers for men born 1951-1967. Intelligence 84: 101514

37. Kong, A., Frigge, M. L., Thorleifsson, G., Stefansson, H., Young, A. I., Zink, F., Jonsdottir, G. A., Okbay, A., Sulem, P., Masson, G., Gudbjartsson, D. F., Helgason, A., Bjornsdottir, G., Thorsteinsdottir, U., \& Stefansson, K. (2017). Selection against variants in the genome associated with educational attainment. Proc. Natl. Acad. Sci. U.S.A. 114(5): E727-E732.

38. Lavely, W. and Freedman, R. (1990). The origins of the Chinese fertility decline. Demography 27(3): 357-367

39. Liu, G. and Vikat, A. (2007). Does divorce risk in Sweden depend on spouses' relative income? A study of marriages from 1981 to 1998. Can. Stud. Popul. 34(2): 217-240

40. Liu, J. and Liu, T. (2020). Two-child policy, gender income and fertility choice in China. Int. Rev. Econ. Finance 69: 1071-1081

41. Maertens, A. (2013). Social norms and aspirations: Age of marriage and education in rural india. World Development, 47, 1-15.

42. McQuillan, K. (2004). When Does Religion Influence Fertility? Popul Dev Rev 30(1): 25-56

43. Mealey, L. (1985). The relationship between social status and biological success: A case study of the Mormon religious hierarchy. Ethol Sociobiol 6(4): 249-257

44. Mills, M., Rindfuss, R. R., McDonald, P. and Te Velde, E. (2011). Why do people postpone parenthood? Reasons and social policy incentives. Human reproduction update 17(6): 848-860

45. Newson, L., Postmes, T., Lea, S. E. G., Webley, P., Richerson, P. J. and McElreath, R. (2007). Influences on communication about reproduction: the cultural evolution of low fertility. Evo Hum Behav 28(3): 199-210

46. Perusse, D. (1993). Cultural and reproductive success in industrial societies: Testing the relationship at the proximate and ultimate levels. Behav. Brain Sci. 16(2): 267-283

47. Piotrowski, M. and Tong, Y. (2016). Education and fertility decline in China during transitional times: A cohort approach. Soc. Sci. Res 55: $94-$ 110

48. Qian, Y. and Jin, Y. (2018). Women's Fertility Autonomy in Urban China: The Role of Couple Dynamics Under the Universal Two-Child Policy. Chin Sociol Rev 50(3): 275-309

49. Schwartz CR, Gonalons-Pons P. (2016). Trends in relative earnings and marital dissolution: Are wives who outearn their husbands still more likely to divorce? RSF Russell Sage Found. J. Soc. Sci. 2(4):218-36

50. Schwartz CR, Han H. (2014). The reversal of the gender gap in education and trends in marital dissolution. Am. Sociol. Rev. 79(4):605-29

51. Shackelford, T. K., Goetz, A. T., Buss, D. M., Euler, H. A. and Hoier, S. (2005). When we hurt the ones we love: Predicting violence against women from men's mate retention. Pers Relatsh 12(4): 447-463

52. Takeuchi, M. and Otani, Y. (2007). Cost of Motherhood| Effects of childbirth on Women's and Couple's earnings (in Japanese), Osaka School of International Public Policy, Osaka University.

53. Talhelm, T. and English, A. S. (2020). Historically rice-farming societies have tighter social norms in China and worldwide. Proc. Natl. Acad. Sci. U.S.A. 117(33): 19816-19824

54. Telford, T. A. (1992). Covariates of Men's Age at First Marriage: The Historical Demography of Chinese Lineages. Population Studies 46(1): 19-35

55. Torr B. M. (2011). The changing relationship between education and marriage in the United States, 1940-2000. Journal of family history, 36(4): 483-503.

56. Trivers, R. L. (1972). Parental investment and sexual selection. In B. Campbell (ed) Sexual Selection and the Descent of Man, Aldinc, Chicago, pp 136-179

57. Van Den Berghe, P. L. (1960). Hypergamy, hypergenation, and miscegenation. Hum Relat 13(1): 83-91

58. Vining, D. R. (1986). Social versus reproductive success: The central theoretical problem of human sociobiology. Behav Brain Sci 9(1): 167187

59. Wang, C. (2012). History of the Chinese Family Planning program: 1970-2010. Contraception 85(6): 563-569

Page $11 / 17$ 
60. Wilder, J. A., Mobasher, Z. and Hammer, M. F. (2004). Genetic evidence for unequal effective population sizes of human females and males. Mol. Biol. Evol 21(11): 2047-2057

61. Yang, D. T. (2002). "What has caused regional inequality in China?" China Economic Review 13(4): 331-334.

62. Zhang, Y., Sun, Q. and Liu, Y. (2021). Social Capital Mediates the Effect of Socioeconomic Status on Prosocial Practices: Evidence from the CGSS 2012 Survey. J Community Appl Soc Psychol: 1-14.

63. Zheng, Y., Yuan, J., Xu, T., Chen, M., Liang, H., Connor, D., Gao, Y., Sun, W., Shankar, N., Lu, C. and Jiang, Y. (2016). Socioeconomic status and fertility intentions among Chinese women with one child. Hum Fertil 19(1): 43-47

64. Gagnon, D. R., S. Doron-Lamarca, M. Bell, T. J. O'Farrell and C. T. Taft (2008). "Poisson regression for modeling count and frequency outcomes in trauma research." Journal of Traumatic Stress 21(5): 448-454.

\section{Tables}

Table 1 Income and Education Predicted Mating Success Differently for Men and Women

\begin{tabular}{|c|c|c|c|c|c|c|c|c|c|c|c|c|}
\hline & \multicolumn{6}{|c|}{ Being Unmarried ( $N=50,631,25,788$ women) } & \multicolumn{6}{|c|}{ Marriage Disruption ( $\mathrm{N}=45,143,23,582$ women) } \\
\hline & Both & & Men & & Women & & Both & & Men & & Women & \\
\hline & $B$ & $S E$ & $B$ & $S E$ & $B$ & $S E$ & $B$ & $S E$ & $B$ & $S E$ & $B$ & $S E$ \\
\hline \multicolumn{13}{|l|}{ Fixed effects } \\
\hline (intercept) & $-5.61^{\star * \star}$ & 0.72 & $-4.91^{\star \star *}$ & 0.10 & $-6.77^{\star \star \star}$ & 0.81 & $-6.99^{\star \star *}$ & 0.17 & $-6.92^{\star \star \star}$ & 0.19 & $-7.86^{\star \star \star}$ & 0.26 \\
\hline Sex-Women & $-0.97^{\star \star \star}$ & 0.04 & & & & & $-0.42^{\star \star \star}$ & 0.06 & & & & \\
\hline Income(std) & $-0.44^{\star \star \star}$ & 0.02 & $-0.52^{\star \star \star}$ & 0.02 & $0.08^{\star \star}$ & 0.03 & $-0.11^{\text {k* }}$ & 0.04 & $-0.11^{\star *}$ & 0.04 & $0.26^{\star \star \star}$ & 0.06 \\
\hline Education. (std) & $-0.49^{\star \star \star}$ & 0.04 & $-1.60^{\star \star *}$ & 0.04 & -0.02 & 0.08 & -0.04 & 0.06 & $-0.17^{\star \star}$ & 0.06 & $0.39^{\star * *}$ & 0.08 \\
\hline$<$ High School & $-0.82^{\star \star \star}$ & 0.07 & $-2.67^{\star \star *}$ & 0.07 & $-1.03^{\star \star \star}$ & 0.12 & $-0.19^{*}$ & 0.09 & $-0.36^{\star \star \star}$ & 0.11 & 0.11 & 0.14 \\
\hline $\begin{array}{l}\text { College and } \\
\text { bachelor }\end{array}$ & $0.93^{\star \star \star}$ & 0.07 & $2.89^{\star \star *}$ & 0.07 & $0.52^{\star \star *}$ & 0.13 & $-0.72^{\star \star \star}$ & 0.11 & $-0.48^{\star \star \star}$ & 0.14 & $-1.069^{\star \star *}$ & 0.17 \\
\hline $\begin{array}{l}\text { Graduate and } \\
\text { above }\end{array}$ & $1.53^{\star \star \star}$ & 0.14 & $4.20^{\star \star \star}$ & 0.15 & $0.90^{\star * \star}$ & 0.24 & $-0.77^{\star *}$ & 0.30 & $-1.00^{+}$ & 0.52 & $-0.88^{*}$ & 0.39 \\
\hline Sex*Income(std) & $0.50^{\star \star \star}$ & 0.04 & & & & & $0.36^{* \star *}$ & 0.07 & & & & \\
\hline Sex*Education(std) & $0.35^{\star \star \star}$ & 0.04 & & & & & $0.23^{\star \star \star}$ & 0.06 & & & & \\
\hline Random effects & $I C C$ & $S D$ & $I C C$ & $S D$ & $I C C$ & $S D$ & $I C C$ & $S D$ & $I C C$ & $S D$ & $I C C$ & $S D$ \\
\hline Region & .03 & 0.48 & .03 & 0.48 & .03 & 0.60 & .12 & 0.67 & .08 & 0.55 & .28 & 1.16 \\
\hline Cohort & .62 & 2.37 & .62 & 2.37 & .66 & 2.66 & .04 & 0.41 & .05 & 0.45 & .05 & 0.49 \\
\hline \multicolumn{13}{|l|}{ Model fit } \\
\hline $\mathrm{AIC}$ & 19444.26 & & 12251.07 & & 7057.00 & & 12554.19 & & 7204.58 & & 5286.85 & \\
\hline $\mathrm{BIC}$ & 19541.42 & & 12316.03 & & 7122.26 & & 12650.18 & & 7268.41 & & 5351.39 & \\
\hline $\begin{array}{l}\text { Pseudo } R^{2} \text { fixed/ } \\
\text { total }\end{array}$ & $.07 / .66$ & & $.04 / .64$ & & $.04 / .70$ & & $.03 / .19$ & & $.02 / .15$ & & $.04 / .35$ & \\
\hline
\end{tabular}

Note. Income(std) and Education(std) refers to scaled annual income and education, respectively. Higher school and equivalent was the reference category for absolute education level. Region refers to the provincial region where the interviewee resided. Cohort refers to birth cohorts in 5-year intervals starting from 1945. $p$ values were calculated using the Satterthwaite approximation method.

${ }^{\star \star \star} p<.001,{ }^{* \star} p<.01 .{ }^{*} p<.05$

Table 2 Income and Education Predicted Fertility (Number of Children) Differently for Men and Women-A 


\begin{tabular}{|c|c|c|c|c|c|c|}
\hline \multirow{2}{*}{ Predictors } & \multicolumn{2}{|c|}{ All $(N=50,475)$} & \multicolumn{2}{|c|}{ Men $(N=24,770)$} & \multicolumn{2}{|c|}{ Women $(N=25,705)$} \\
\hline & $B$ & $S E$ & $B$ & $S E$ & $B$ & $S E$ \\
\hline \multicolumn{7}{|l|}{ Fixed effects } \\
\hline (intercept) & $-3.68^{\text {*kk }}$ & 0.15 & $-3.72^{* k k}$ & 0.17 & $-3.58^{* k \hbar}$ & 0.13 \\
\hline Sex-Women & $-0.10^{\text {*k* }}$ & 0.01 & & & & \\
\hline Income(std) & $0.03^{\star \star * k}$ & 0.01 & $0.03^{\star \star k *}$ & 0.01 & $-0.04^{\star \star \star}$ & 0.01 \\
\hline Education. (std) & $0.01^{+}$ & 0.01 & $0.03^{* *}$ & 0.01 & $-0.05^{\star \star k}$ & 0.01 \\
\hline$<$ High School & $0.11^{\star \star *}$ & 0.01 & $0.11^{\star * *}$ & 0.02 & $0.15^{\star \star *}$ & 0.02 \\
\hline College and bachelor & $-0.19^{* k *}$ & 0.02 & $-0.26^{* * k}$ & 0.02 & $-0.13^{* k \hbar}$ & 0.03 \\
\hline Graduate and above & $-0.31^{\star \star *}$ & 0.06 & $-0.41^{\text {t*k }}$ & 0.08 & $-0.22^{* *}$ & 0.09 \\
\hline Sex*Income(std) & $-0.06^{\star \star \star}$ & 0.01 & & & & \\
\hline Sex*Education(std) & $-0.06^{* \star *}$ & 0.01 & & & & \\
\hline \multicolumn{7}{|l|}{ Random effects } \\
\hline & $I C C$ & $S D$ & $I C C$ & $S D$ & $I C C$ & $S D$ \\
\hline Region & .05 & 0.25 & .04 & 0.24 & .05 & 0.25 \\
\hline Cohort & .18 & 0.48 & .22 & 0.55 & .14 & 0.41 \\
\hline \multicolumn{7}{|l|}{ Model fit } \\
\hline AIC & 124570.01 & & 63570.98 & & 61106.08 & \\
\hline $\mathrm{BIC}$ & 124667.14 & & 63635.92 & & 61171.31 & \\
\hline Pseudo $\mathrm{R}^{2} \mathrm{fixed} /$ total & $.02 / .32$ & & $.02 / .34$ & & $.03 / .29$ & \\
\hline
\end{tabular}

Note. Income(std) and Education(std) refers to scaled annual income and education, respectively. Higher school and equivalent was the reference category for absolute education level. Region refers to the provincial region where the interviewee resided. Cohort refers to birth cohorts in 5-year intervals starting from 1945. $p$ values were calculated using the Satterthwaite approximation method.

${ }^{\star \star \star} p<.001,{ }^{* \star} p<.01 .{ }^{+} p<.10$.

Table 3 Income and Education Predicted Fertility Differently for Men and Women-B 


\begin{tabular}{|c|c|c|c|c|c|c|c|c|c|c|c|c|}
\hline & \multicolumn{4}{|c|}{$\begin{array}{l}\text { At least } 1 \text { child among first-time } \\
\text { married }\end{array}$} & \multicolumn{4}{|c|}{$\begin{array}{l}\text { At least } 2 \text { children among who had } 1 \\
\text { child }\end{array}$} & \multicolumn{4}{|c|}{$\begin{array}{l}\text { At least } 3 \text { children among who had } 2 \\
\text { children }\end{array}$} \\
\hline & \multicolumn{2}{|c|}{$\operatorname{Men}(N=24,843)$} & \multicolumn{2}{|c|}{$\begin{array}{l}\text { Women }(\mathrm{N}= \\
25,788)\end{array}$} & \multicolumn{2}{|c|}{ Men $(N=20,877)$} & \multicolumn{2}{|c|}{$\begin{array}{l}\text { Women }(\mathrm{N}= \\
22,981)\end{array}$} & \multicolumn{2}{|c|}{ Men $(N=10,540)$} & \multicolumn{2}{|c|}{$\begin{array}{l}\text { Women }(\mathrm{N} \\
=12,004)\end{array}$} \\
\hline & $B$ & $S E$ & $B$ & $S E$ & $B$ & $S E$ & $B$ & $S E$ & $B$ & $S E$ & $B$ & $S E$ \\
\hline Fixed effects & & & & & & & & & & & & \\
\hline (intercept) & $-1.95^{\star \star \star}$ & 0.48 & $-1.23^{*}$ & 0.58 & $-3.82^{* k *}$ & 0.19 & $-3.92^{* k *}$ & 0.33 & $-5.47^{* k *}$ & 0.12 & $-5.62^{* \star k}$ & 0.15 \\
\hline Income(std) & $0.34^{\star \star *}$ & 0.02 & $-0.23^{\star \star \star *}$ & 0.03 & -0.02 & 0.02 & $-0.15^{\star \star * k}$ & 0.02 & $-0.04^{*}$ & 0.02 & $-0.04^{*}$ & 0.02 \\
\hline Education. (std) & $0.39^{\star \star \star}$ & 0.05 & -0.01 & 0.06 & $-0.10^{* *}$ & 0.03 & $-0.40^{\star \star * k}$ & 0.03 & 0.01 & 0.03 & $-0.09^{* \star \star}$ & 0.02 \\
\hline$<$ High School & $0.47^{\star \star \star *}$ & 0.09 & $0.92^{* k *}$ & 0.10 & $0.34^{\star * *}$ & 0.06 & $0.38^{\star \star *}$ & 0.07 & 0.09 & 0.07 & $0.30^{\star *}$ & 0.09 \\
\hline $\begin{array}{l}\text { College and } \\
\text { bachelor }\end{array}$ & $-0.98^{\star \star \star}$ & 0.09 & $-0.51^{\star \star *}$ & 0.11 & $-0.66^{* k *}$ & 0.08 & 0.13 & 0.09 & $-0.51^{* *}$ & 0.13 & -0.31 & 0.19 \\
\hline $\begin{array}{l}\text { Graduate and } \\
\text { above }\end{array}$ & $-1.72^{* *}$ & 0.17 & $-0.87^{\star \star \star}$ & 0.21 & -0.12 & 0.26 & $1.07^{* k *}$ & 0.28 & -0.10 & 0.51 & -0.64 & 0.96 \\
\hline \multicolumn{13}{|l|}{ Random effects } \\
\hline & $I C C$ & $S D$ & $I C C$ & $S D$ & $I C C$ & $S D$ & $I C C$ & $S D$ & $I C C$ & $S D$ & $I C C$ & $S D$ \\
\hline Region & .04 & 0.49 & .06 & 0.65 & .22 & 1.00 & .27 & 1.25 & .15 & 0.44 & .17 & 0.47 \\
\hline Cohort & .40 & 1.55 & .49 & 1.89 & .04 & 0.42 & .15 & 0.92 & .06 & 0.28 & .09 & 0.34 \\
\hline \multicolumn{13}{|l|}{ Model fit } \\
\hline AIC & 13656.81 & & 8358.82 & & 21119.72 & & 19653.27 & & 13227.84 & & 14326.70 & \\
\hline $\mathrm{BIC}$ & 13721.77 & & 8424.08 & & 21183.30 & & 19717.61 & & 13285.95 & & 14385.84 & \\
\hline $\begin{array}{l}\text { Pseudo } R^{2} \text { fixed/ } \\
\text { total }\end{array}$ & $.05 / .47$ & & $.0 / .57$ & & $.04 / .29$ & & $.05 / .45$ & & $.01 / .14$ & & $.02 / .18$ & \\
\hline
\end{tabular}

Note. Income(std) and Education(std) refers to scaled annual income and education, respectively. Higher school and equivalent was the reference category for absolute education level. Region refers to the provincial region where the interviewee resided. Cohort refers to birth cohorts in 5-year intervals starting from 1945. $p$ values were calculated using the Satterthwaite approximation method.

${ }^{\star * \star} p<.001,{ }^{* \star} p<.01 .{ }^{*} p<.05$.

Table 4 Relative Status Predicted Childbirth for First-time Married Men and Women 


\begin{tabular}{|c|c|c|c|c|c|c|c|c|c|c|c|c|}
\hline & \multicolumn{4}{|c|}{$\begin{array}{l}\text { At least } 1 \text { child among first-time } \\
\text { married }\end{array}$} & \multicolumn{4}{|c|}{$\begin{array}{l}\text { At least } 2 \text { children among who had } 1 \\
\text { child }\end{array}$} & \multicolumn{4}{|c|}{$\begin{array}{l}\text { At least } 3 \text { children among who had } 2 \\
\text { children }\end{array}$} \\
\hline & \multicolumn{2}{|l|}{$\begin{array}{l}\text { Men }(N= \\
18,013)\end{array}$} & \multicolumn{2}{|c|}{$\begin{array}{l}\text { Women }(N= \\
19,432)\end{array}$} & \multicolumn{2}{|c|}{ Men $(N=17,255)$} & \multicolumn{2}{|c|}{$\begin{array}{l}\text { Women }(\mathrm{N} \\
=18,740)\end{array}$} & \multicolumn{2}{|c|}{ Men $(N=8,661)$} & \multicolumn{2}{|c|}{$\begin{array}{l}\text { Women }(\mathrm{N}= \\
9,599)\end{array}$} \\
\hline & $B$ & $S E$ & $B$ & $S E$ & $B$ & $S E$ & $B$ & $S E$ & $B$ & $S E$ & $B$ & $S E$ \\
\hline \multicolumn{13}{|l|}{ Fixed effects } \\
\hline (intercept) & -0.04 & 0.46 & $1.18^{*}$ & 0.46 & $-2.85^{\star \star \star}$ & 0.22 & $-2.24^{\text {*k* }}$ & 0.30 & $-4.87^{\star \star \star}$ & 0.23 & $-4.18^{\star \star \star}$ & 0.26 \\
\hline Income Difference & $0.06^{* * *}$ & 0.01 & $-0.09^{\star \star \star}$ & 0.01 & $0.03^{\star \star \star}$ & 0.01 & $-0.03^{\text {**k }}$ & 0.01 & -0.00 & 0.01 & -0.00 & 0.01 \\
\hline $\begin{array}{l}\text { Education } \\
\text { Difference }\end{array}$ & $0.08^{* k *}$ & 0.02 & 0.01 & 0.02 & $0.06^{* k *}$ & 0.01 & $-0.03^{* k \hbar}$ & 0.01 & $0.08^{* k *}$ & 0.01 & $-0.05^{\star \star \star k}$ & 0.01 \\
\hline Household Income & $0.07^{+}$ & 0.04 & 0.03 & 0.04 & -0.00 & 0.02 & -0.02 & 0.02 & -0.03 & 0.02 & $-0.07^{* k k}$ & 0.02 \\
\hline Education Average & $-0.14^{* k \star}$ & 0.02 & $-0.20^{* k k}$ & 0.02 & $-0.28^{\text {*k* }}$ & 0.01 & $-0.27^{\star \star * k}$ & 0.01 & $-0.22^{\star \star \star}$ & 0.02 & $-0.20^{\text {thk }}$ & 0.02 \\
\hline \multicolumn{13}{|l|}{ Random effects } \\
\hline & $I C C$ & $S D$ & $I C C$ & $S D$ & $I C C$ & $S D$ & $I C C$ & $S D$ & $I C C$ & $S D$ & $I C C$ & $S D$ \\
\hline Region & .05 & 0.53 & .04 & 0.45 & .19 & 0.91 & .229 & 1.08 & .12 & 0.70 & .17 & 0.89 \\
\hline Cohort & .36 & 1.42 & .37 & 1.44 & .06 & 0.52 & .129 & 0.81 & .07 & 0.53 & .10 & 0.67 \\
\hline \multicolumn{13}{|l|}{ Model fit } \\
\hline AIC & 4351.29 & & 3641.04 & & 16480.40 & & 15700.91 & & 8294.26 & & 8259.11 & \\
\hline $\mathrm{BIC}$ & 4405.88 & & 3696.17 & & 16534.69 & & 15755.78 & & 8343.73 & & 8309.29 & \\
\hline $\begin{array}{l}\text { Pseudo } \mathrm{R}^{2} \text { fixed/ } \\
\text { total }\end{array}$ & $.05 / .44$ & & $.07 / .45$ & & $.12 / .34$ & & $.09 / .42$ & & $.05 / .23$ & & $.04 / .30$ & \\
\hline
\end{tabular}

Note. Income difference and education difference were calculated using uncentered and unscaled annual income and education level, with a higher value indicating a higher relative status compared with one's partner. Education Average refers to the average absolute education level of the couple. Region refers to the provincial region where the interviewee resided. Cohort refers to birth cohorts in 5-year intervals starting from 1945. $p$ values were calculated using the Satterthwaite approximation method. ${ }^{\star \star *} p<.001,{ }^{* \star} p<.01 .{ }^{*} p<.05$.

Table 5 Relative Socioeconomic Status (vs. Partners) Predict Age of First Marriage 


\begin{tabular}{|c|c|c|c|c|c|c|c|c|}
\hline & \multicolumn{4}{|c|}{ Age at First Marriage } & \multicolumn{4}{|c|}{$\begin{array}{l}\text { Partner's Age at First Marriage } \\
\text { Women }(N=19,533) \text { women })\end{array}$} \\
\hline & \multicolumn{2}{|c|}{$\operatorname{Men}(N=18,020)$} & \multicolumn{2}{|c|}{ Women $(N=19,511)$ women $)$} & \multicolumn{2}{|c|}{$\operatorname{Men}(N=17,947)$} & \multicolumn{2}{|c|}{ Women $(N=19,455)$ women } \\
\hline & $B$ & $S E$ & $B$ & $S E$ & $B$ & $S E$ & $B$ & $S E$ \\
\hline \multicolumn{9}{|l|}{ Fixed effects } \\
\hline (intercept) & $24.17^{\star \star \star}$ & 0.60 & $21.87^{\star \star \star}$ & 0.30 & $7.89^{\star \star \star}$ & 0.19 & $8.38^{* \star k *}$ & 0.21 \\
\hline Income Difference & $-0.02^{\star \star \star}$ & 0.01 & $0.01^{+}$ & 0.01 & $-0.02^{\star \star *}$ & 0.01 & $-0.01^{+}$ & 0.01 \\
\hline Education Difference & $-0.06^{\star * *}$ & 0.01 & $0.08^{* * *}$ & 0.01 & $-0.05^{\star \star \star}$ & 0.01 & $-0.05^{* k *}$ & 0.01 \\
\hline Age at First Marriage & & & & & $0.61^{* \star *}$ & 0.01 & $0.72^{* \star *}$ & 0.01 \\
\hline \multicolumn{9}{|l|}{ Random effects } \\
\hline & $I C C$ & $S D$ & $I C C$ & $S D$ & $I C C$ & $S D$ & $I C C$ & $S D$ \\
\hline Region & 0.08 & 1.16 & 0.17 & 1.32 & .076 & 0.72 & 0.06 & 0.71 \\
\hline Cohort & 0.20 & 1.88 & 0.06 & 0.79 & .017 & 0.34 & 0.01 & 0.25 \\
\hline Residual & & 3.58 & & 2.83 & & 2.47 & & 2.90 \\
\hline \multicolumn{9}{|l|}{ Model fit } \\
\hline AIC & 100182.12 & & 100641.00 & & 86437.64 & & 101223. & \\
\hline $\mathrm{BIC}$ & 100228.92 & & 100688.27 & & 86492.21 & & 101278. & \\
\hline Pseudo $\mathrm{R}^{2}$ fixed/ total & $.002 / .28$ & & $.004 / .23$ & & $.46 / .51$ & & $.39 / .43$ & \\
\hline
\end{tabular}

Note. Income difference and education difference were calculated using uncentered and unscaled annual income and education level, with a higher value indicating a higher relative status compared with one's partner. Region refers to the provincial region where the interviewee resided. Cohort refers to birth cohorts in 5-year intervals starting from 1945.

$\mathrm{p}$ values were calculated using the Satterthwaite approximation method.

${ }^{* \star *} p<.001 .{ }^{* *} p<.01 .{ }^{\star} p<.05$.

\section{Figures}



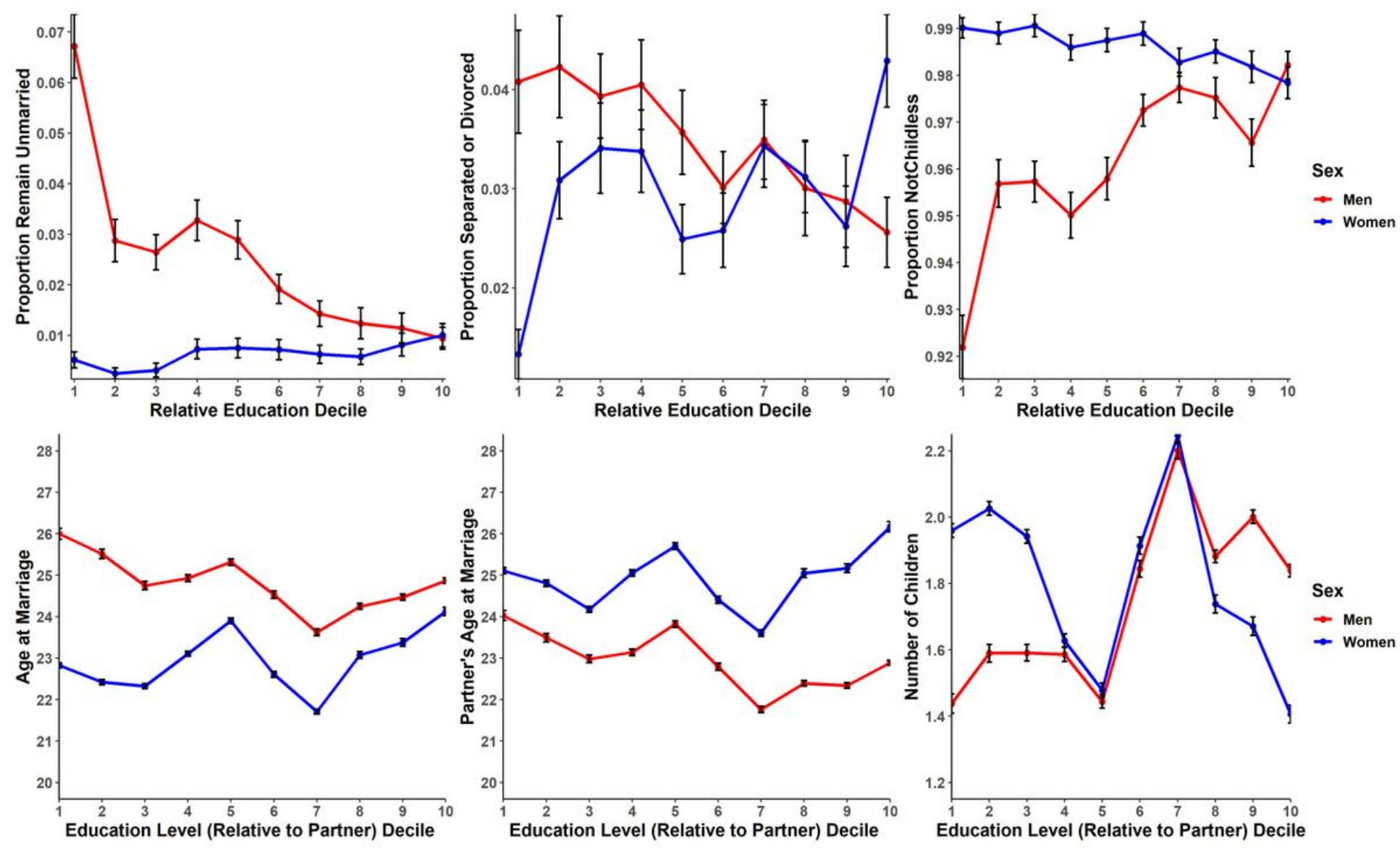

Figure 1

Mating and Reproduction along Social Status and Relative Status between Couples

Age at first marriage was plotted using all cases while the mating as well as the reproductive outcome was plotted using only cases with age $\geq$ 40. The upper panels indicate that higher status men are less likely to be unmarried, going through marriage disruption or childless while the patterns are the opposite for women.

For the lower three panels, decile 1 would indicate the respondent had an extremely lower status compared with their partner while decile 10 extremely higher status compared with their partner. Deciles 5-6 would indicate homogamy in terms of education level. Men who are relatively higher status compared with their spouse married at a younger age and had younger wives. The patterns are the opposite for women. Both hypergamy and homogamy are effective reproductive strategies.

\section{Supplementary Files}

This is a list of supplementary files associated with this preprint. Click to download.

- SupplementaryMaterialsBEASR2.docx 